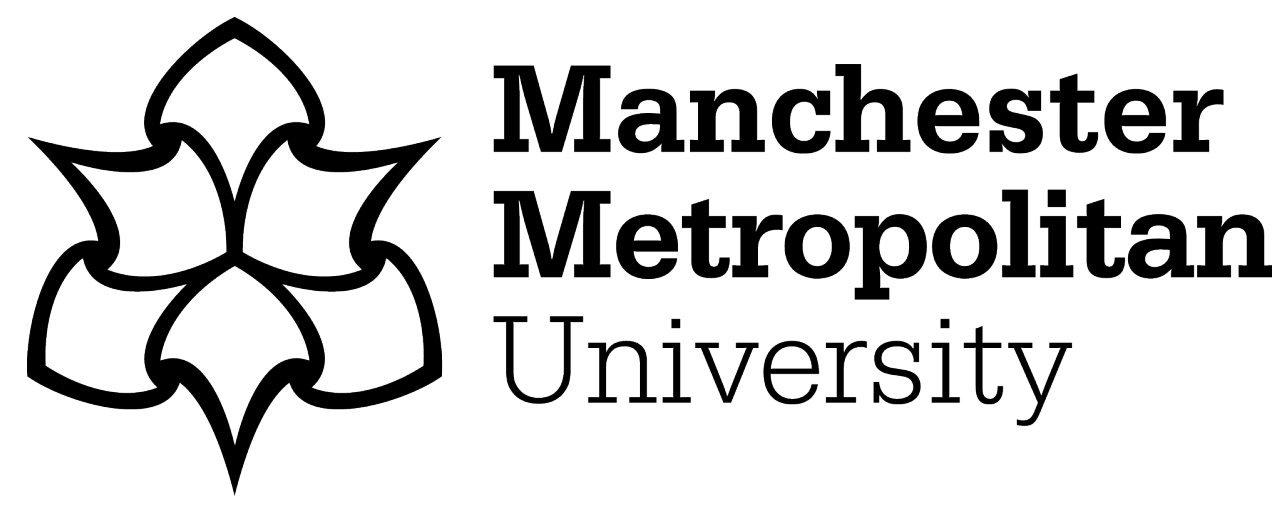

Kinninmonth, M, Liauw, CM, Verran, J, Taylor, RL, Edwards-Jones, V and Shaw, D (2014) Nano-layered inorganic-organic hybrid materials for the controlled delivery of antimicrobials. Macromolecular Symposia, 338 (1). pp. 36-44. ISSN 1022-1360

Downloaded from: https: //e-space.mmu.ac.uk/547/

Version: Accepted Version

Publisher: Wiley-VCH Verlag

DOI: https://doi.org/10.1002/masy.201100109

Please cite the published version 


\title{
Nano-layered inorganic-organic hybrid materials for the controlled delivery of antimicrobials.
}

\author{
Malcolm Kinninmonth, ${ }^{1}$ Christopher Liauw $*,{ }^{1}$ Joanna Verran, ${ }^{2}$ Rebecca \\ Taylor, ${ }^{2}$ Valerie Edwards-Jones, ${ }^{3}$ David Shaw ${ }^{4}$ \\ ${ }^{1}$ School of Engineering, Manchester Metropolitan University, Manchester, \\ M1 5GD, UK. \\ ${ }^{2}$ School of Healthcare Science, Manchester Metropolitan University, Chester \\ Street, Manchester, M1 5GD, UK. \\ ${ }^{3}$ R.E.D. Office, Manchester Metropolitan University, Chester Street, \\ Manchester, M1 5GD, UK. \\ ${ }^{4}$ Technical Manager, Rockwood additives Ltd, Moorfield Road, Widnes, \\ Cheshire, WA8 3AA UK
}

\begin{abstract}
Summary: An essential oil (EO) blend has been identified that provides a broad spectrum potent antimicrobial effect. Adsorption of the EO onto porous silicate materials (Rockwood Additives: Laponite ${ }^{\mathbb{B}}$ B, Laponite ${ }^{\mathbb{R}} \mathrm{RD}$ and Fulcat ${ }^{\circledR} 800$ ) and has been analysed and it was found that Laponite ${ }^{\circledR}$ RD organically modified with dihydrogenated tallow dimethyl ammonium chloride (2HT2M) at 50\% cation exchange capacity gave the highest levels of adsorption. The Laponite ${ }^{\circledR}$ RD 2HT2M with EO blend adsorbed has been added to polymer materials to produce an antimicrobial polymer. The adsorption of the EO onto the Laponite ${ }^{\circledR} \mathrm{RD}$ was done to achieve controlled release of the EO to prolong the antimicrobial effect within the polymer. Addition of the EO loaded substrates into silicone elastomer has resulted in successfully conferring a high level of antimicrobial activity to the polymer.
\end{abstract}

Keywords: Organoclay; Silicones; Essential oil; Antimicrobial; Controlled release

\section{Introduction}

Healthcare-associated infections (HAI) are a significant problem facing the healthcare industry today. In the period from 2009 to 2010 the Health Protection Agency (HPA) for England and Wales reported almost 30,000 cases of infection attributable to either MRSA or Clostridium difficile (two of the most common HAI pathogens). A further 1500 infections were recorded due to surgical site infection [1]. Modern prevention methods are helping to reduce the risk of contracting a HAI but it is important to continue to look for new ways to help combat the problem.

Essential oils (EO), have been shown to be effective in limiting the growth of many 
pathogenic microbes responsible for HAI $[2,3]$. If EO were present on surfaces in healthcare facilities it could reduce the numbers of pathogenic microbes in the environment and therefore reduce the incidence of HAI. EO by their nature are volatile and simply adding them to a surface material would be ineffective as they would evaporate rapidly and the antimicrobial effect would be lost. Encapsulation of EO into a material could overcome the issue of rapid evaporation. If the encapsulation conditions are correct the EO would be able to slowly leach out of the material resulting in a longer lifetime for the antimicrobial effects.

This study aims to adsorb an EO antimicrobial into montmorillonites (MMT). The EO loaded inorganic will then be added to polymers for the manufacture of antimicrobial surfaces. Using an inorganic encapsulation material such as MMT offers advantages such as protection from thermoplastic polymer processing conditions (i.e. heat and shear). As well as being able to tailor the properties of the MMT through cation exchange in order to maximise the level of adsorption. Previous work at MMU has shown MMT can be used as a controlled release reservoir for Triclosan ${ }^{\circledR}[4]$ the EO antimicrobial used in this work should be able to inhibit the growth of a broader range of microbes.

\section{Experimental}

Montmorillonites (MMT) provided by Rockwood Additives Ltd. were analysed for their ability to adsorb three EO (oregano [OO], manuka [MO] and rosewood [RO]). These oils were selected on the basis of preliminary studies which had shown them to have good antimicrobial activity against a number of bacteria, both as individual oils and in blend formulations. Oregano having the highest individual antimicrobial activity and the blend of oregano and rosewood showing the highest activity overall.

Two methods were used to analyse the level of adsorption of the EO onto the MMT, Gas Chromatography (GC) and Fourier Transform Infra Red spectroscopy (FTIR), and Flow Micro-calorimetry (FMC).

For the GC analysis MMT (5 g) was added to heptane (100 ml) (spiked with 5\% dodecane as an internal standard (IS)), the EO (1.25 g) was then added. After stirring for $18 \mathrm{~h}$, the MMT was filtered out and analysed using Diffuse reflectance infrared Fourier transform spectroscopy (DRIFTS) the supernatant liquor was analysed using a HP 5890 series 2 GC with a $60 \mathrm{~m}$ Rtx $^{\circledR}-5$ SILMS column (internal diameter $0.25 \mathrm{~mm}$, film thickness $0.25 \mu \mathrm{m}$ ) 
using helium as a carrier gas. Using calibration graphs for the major components of the oils, the ratio of the EO peaks to the internal standard after adsorption were used to determine the levels of adsorption of the major EO components. Adsorption of the EO onto the MMT was confirmed using DRIFTS.

FMC was used to analyse the heat of adsorption of the EO onto the MMT as well as the mass of EO that was adsorbed, the FMC technique is described elsewhere [4]. The FMC experiments were conducted using heptane as the carrier solvent, the flow rate was $4 \mathrm{~cm}^{3} \mathrm{~h}^{-}$ 1 and the cell temperature was $25 \pm 0.5{ }^{\circ} \mathrm{C}$. The FMC data enabled the total level of adsorption of the EO to be determined. Whereas the GC data identified the adsorption of the key molecules of the EO (any molecule that comprised greater than $1 \%$ of the oil). Adsorption studies were also carried out on a number of organically modified (OM) substrates: Laponite ${ }^{\circledR}$ RD OM with dihydrogenated tallow dimethyl ammonium chloride (2HT2M), Laponite ${ }^{\circledR}$ B OM with 2HT2M, Fulcat ${ }^{\circledR} 800$ OM with 2 HT2M, and Fulcat ${ }^{\circledR} 800$ OM with cetyl trimethyl ammonium chloride (CTAB). Organically modified samples were made at at cation exchange capacities (CEC) of 50, 75 and 100\% for all three of the substrates. The Laponite ${ }^{\circledR}$ samples were OM using a dry mix method. Fulcat ${ }^{\circledR} 800$ 2HT2M samples were made using both dry and wet mix methods and Fulcat ${ }^{\circledR} 800$ CTAB samples were made using a wet mix methods. After modification the substrates were analysed for adsorption of the EO using the same methods as the unmodified substrates.

Silicone elastomer (SE) samples that had been treated with the EO were made and analysed for bactericidal activity against Methicillin resistant Staphylococcus aureus (MRSA) and Acinetobacter baumannii. A number of silicone elastomer (M511 Maxillofacial Silicone, Technovent Ltd) samples were made according to the method described in [4], and poured into a $1 \mathrm{~mm}$ thick square mould. The formulations made were: pure silicone elastomer (SE), SE with EO blend (3.3\%). (SE + EO), SE with Laponite ${ }^{\circledR}$ RD modified with $50 \%$ CEC 2HT2M (LRD50). (SE + LRD50), SE with LRD50 loaded with EO (final oil loading 3.3\%). $(\mathrm{SE}+(\mathrm{LRD} 50+\mathrm{EO}))$, and SE with Laponite ${ }^{\circledR}$ RD modified with $100 \%$ CEC 2HT2M (LRD100) loaded with EO (final oil loading 3.3\%). (SE + (LRD100+ EO)). For the SE+EO sample the ratio of monomer to catalyst had to be adjusted from 10:1 to 8:1 to allow the SE to cure fully.

The SE samples were analysed for their antimicrobial activity by adding $100 \mu 1$ of a bacterial suspension in nutrient broth (containing $1 \times 10^{7}$ bacterial cells per $\mathrm{ml}$ ) to a $1 \mathrm{~cm}^{2}$ plaque of the material to be tested. The broth culture was dried on at $40^{\circ} \mathrm{C}$ for $1.5 \mathrm{~h}$, immediately 
after drying a plaque was sampled by transferring it to $10 \mathrm{ml}$ peptone water containing $0.5 \%$ tween 20 and vortexing for $1 \mathrm{~min}$ (to wash the bacterial cells from the plaque into the peptone water). The peptone water containing the bacterial cells was then plated using a spiral plater and incubated for $24 \mathrm{~h}$. After incubation the number of bacterial colonies was used to determine the number of viable cells on the surface of the SE plaque, and therefore the level of bactericidal activity. This process was carried out with plaques at time periods of 2, 6 and $24 \mathrm{~h}$ after the initial drying phase.

\section{RESULTS}

Three acid treated MMT (Fulcat ${ }^{\circledR} 400$, Fulcat ${ }^{\circledR} 435$ and Fulacolor $\left.{ }^{\circledR}\right)$, two Laponites ${ }^{\circledR}(\mathrm{B}$ and RD) and a chemically modified MMT (Fulcat ${ }^{\circledR}$ 800) were initially analysed for their adsorption properties using GC.

Initial studies with RO appeared to give high levels of adsorption of major components onto the acid treated clays. With the GC peaks attributed to Linalool, Linalool oxide and $\alpha$ Terpineol all showing dramatic reduction in size after adsorption as shown in Figures 1 and 2.

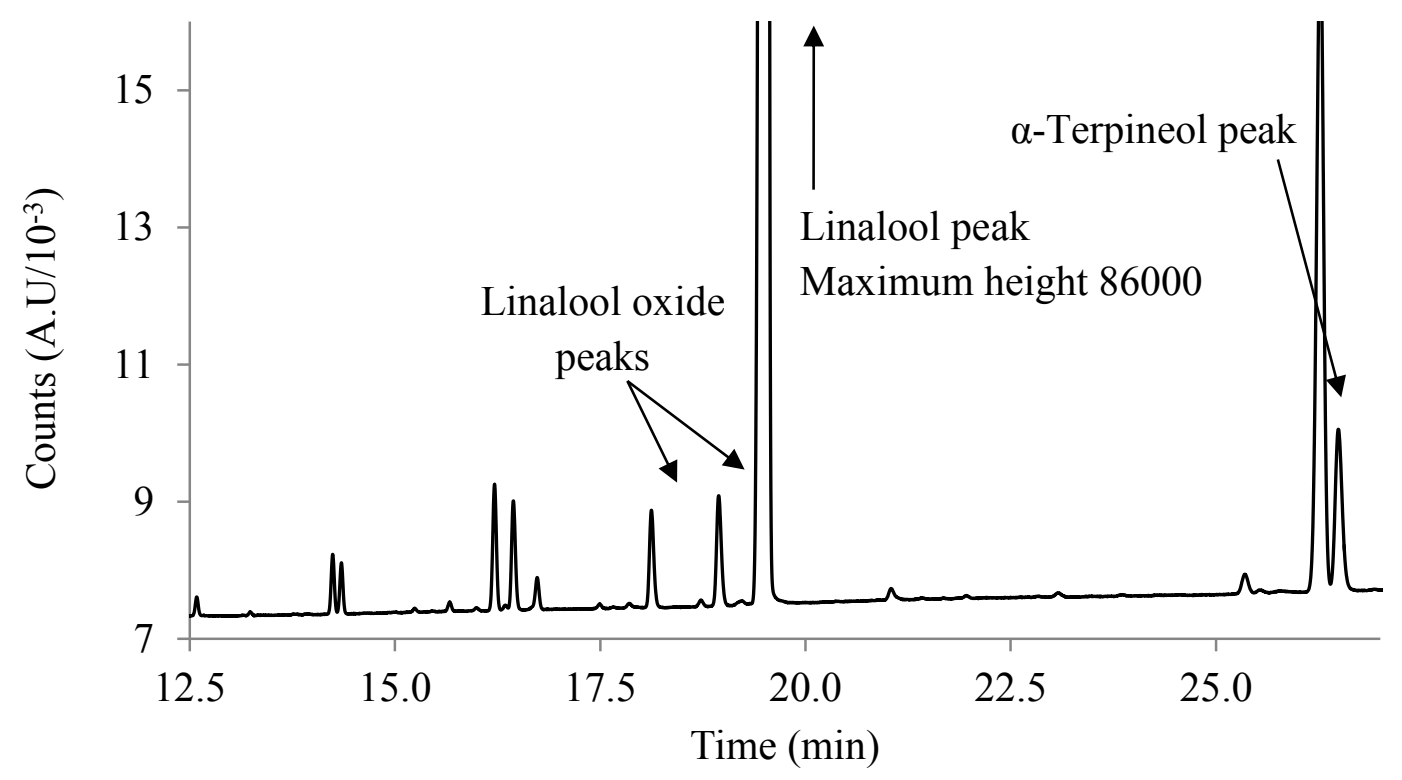

Figure 1. Gas chromatograph for Rosewood oil before adsorption onto montmorillonite. 


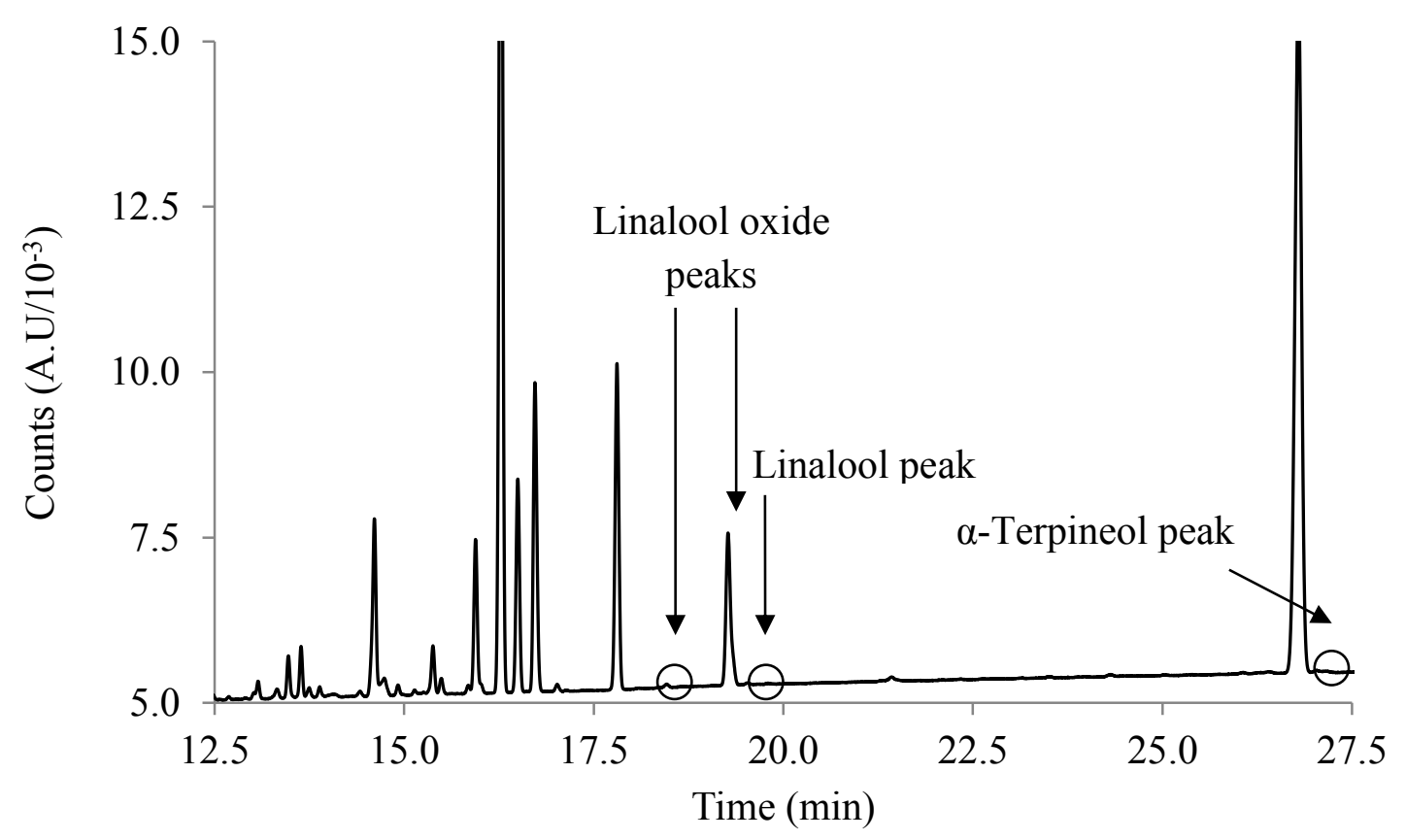

Figure 2. Gas chromatograph for Rosewood oil after adsorption onto acid treated montmorillonite, showing lack of linalool, linalool oxide and $\alpha$-terpineol peaks.

DRIFTS analysis of the acid treated MMT after adsorption suggested that the removal of these peaks was due to damage of the oil rather than adsorption of the components from the mother liquor. Before adsorption in the range $1300-1500 \mathrm{~cm}^{-1}$ for RO there are three distinct adsorption bands; after adsorption of RO only two of these adsorption bands remained (Figure 3). GC analysis of RO adsorbed onto Fulcat ${ }^{\circledR} 800$ and the Laponites ${ }^{\circledR}$ showed the reduction in the linalool, linalool oxide and $\alpha$-terpineol peaks to be lower in relation to the acid treated MMT, however DRIFTS analysis of the samples after adsorption showed no evidence of damage to the RO with all three adsorption bands in the $1300-1500 \mathrm{~cm}^{-1}$ region being present (Figure 4). This data suggested that the acid treated MMT would be unsuitable for EO encapsulation, and all subsequent adsorption work was carried out only with just Fulcat $^{\circledR} 800$ and the Laponite ${ }^{\circledR}$ samples. 


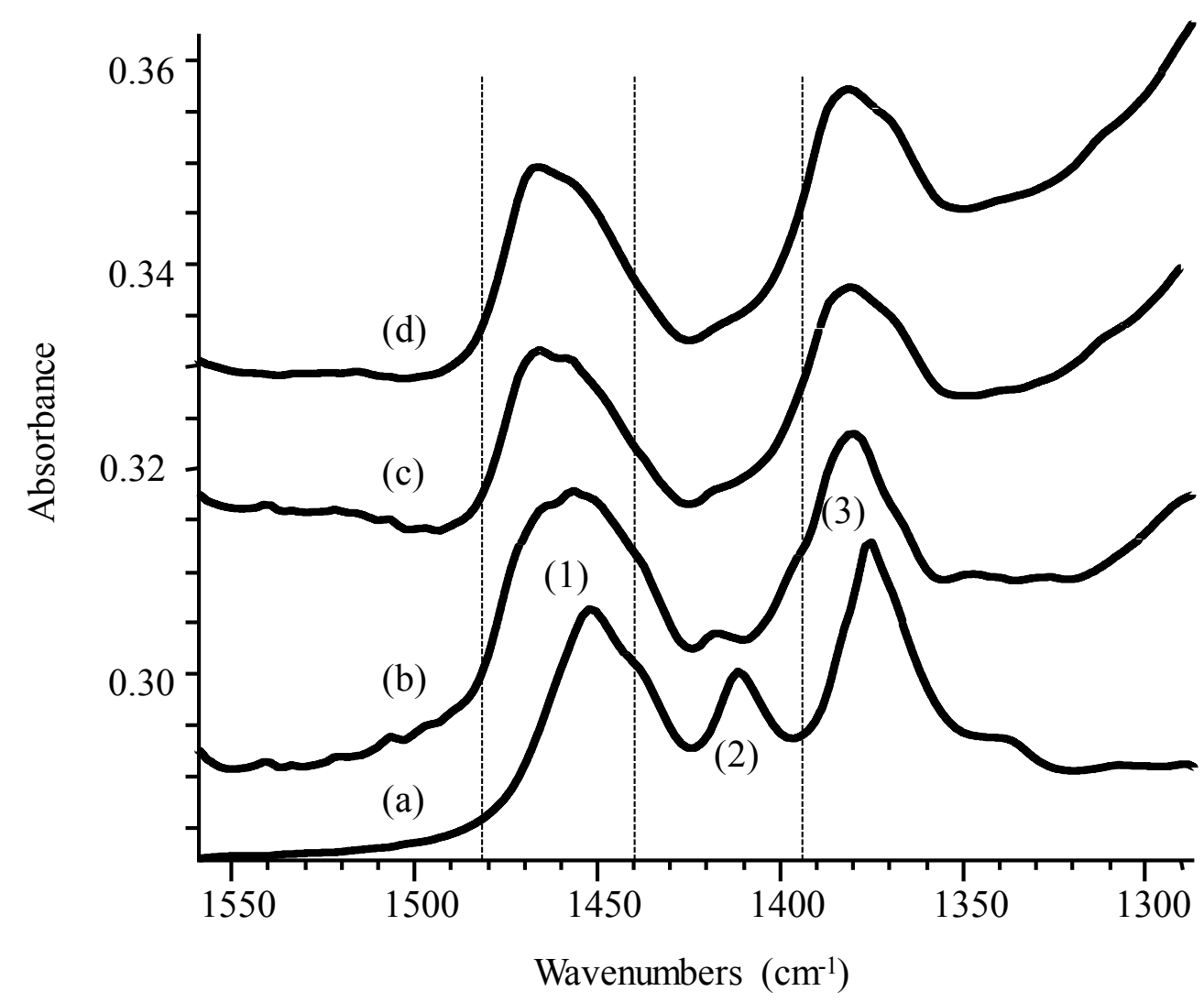

Figure 3. FTIR profile of RO after adsorption onto acid treated MMT, showing lack of central peak (peak 2). (a) Rosewood oil, (b) Fulacolor ${ }^{\circledR}$ Rosewood oil adsorbed, (c) Fulcat ${ }^{\circledR}$ 435 Rosewood oil adsorbed, (d) Fulcat ${ }^{\circledR} 400$ Rosewood oil adsorbed.

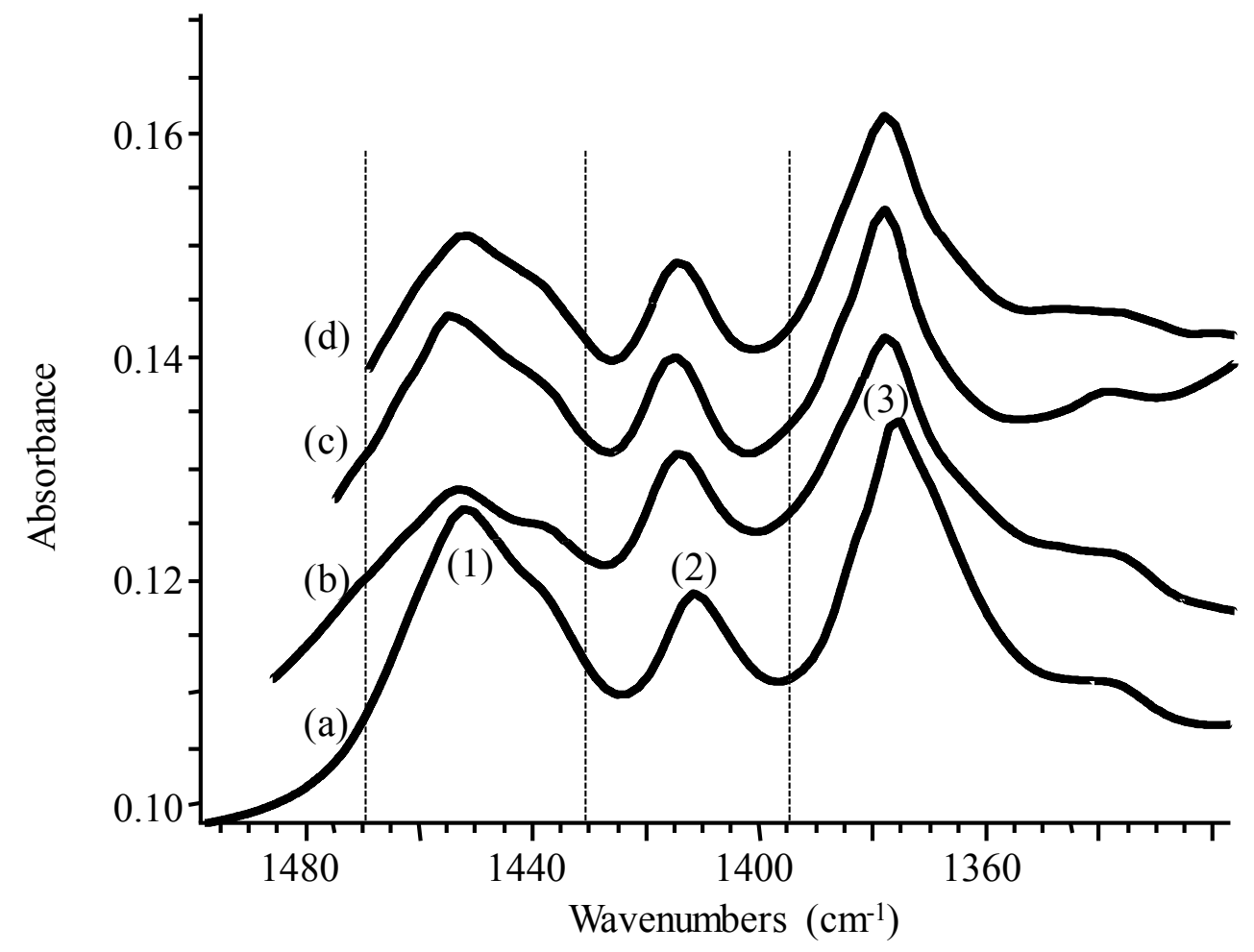

Figure 4. FTIR profile of RO after adsorption onto substrates that were not acid treated , central peak (peak 2) present for all samples. (a) Rosewood oil, (b) Laponite $\mathrm{B}^{\circledR}$ Rosewood 
oil adsorbed, (c) Laponite RD ${ }^{\circledR} 435$ Rosewood oil adsorbed, (d) Fulcat ${ }^{\circledR} 800$ Rosewood oil adsorbed.

The adsorption studies using gas chromatography (GC) enabled analysis of the effect of adsorption on specific components of the oils. It was decided that only molecules that counted for more than $1 \%$ of the EO would be analysed for adsorption, as the peak areas for any molecules of $>1 \%$ would be too small to enable for accurate readings. The results of the GC adsorption studies are shown in Figure 5.

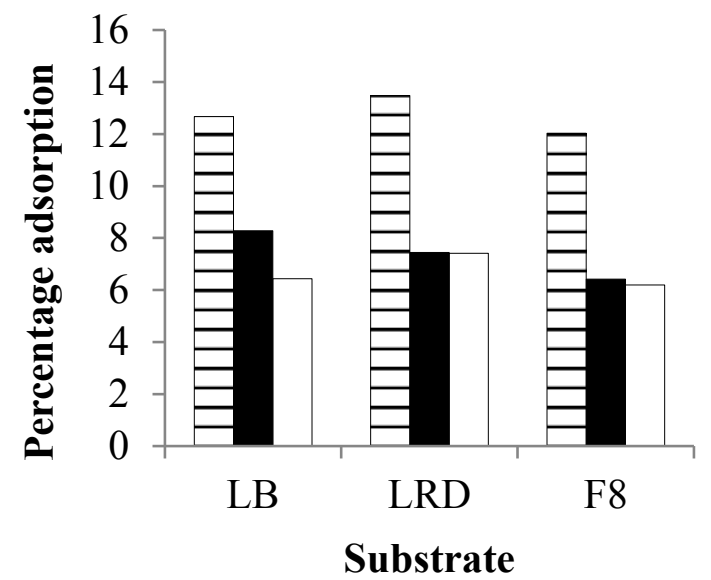

Figure 5. Adsorption levels (mass of oil/mass of substrate) as determined by GC analysis.

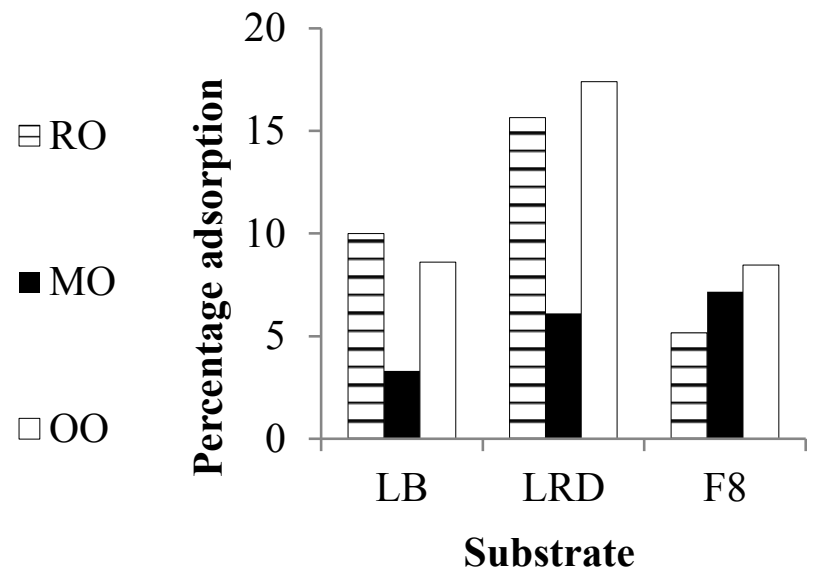

Figure 6. Adsorption levels (mass of oil/mass of substrate) as determined by FMC analysis.

Of the three oils tested RO gave the highest levels of adsorption for all thee substrates. This is likely to be because the counter-ions on the surface of the substrate and platelet edge hydroxyl groups create a polar environment suitable for the adsorption of the polar molecules which comprise the majority of RO. Manuka and Oregano showed lower levels of adsorption which can be attributed to the lower polarity and increased molecular size of the majority of the oil components relative to those in. The lower overall polarity will reduce adsorption and the increased molecular size will restrict entry to the MMT galleries.

When comparing the substrates we found that they all gave similar levels of adsorption with Laponite ${ }^{\circledR}$ RD perhaps performing slightly better than the other two.

Adsorption studies were also carried out using flow micro calorimetry (FMC) which allowed us to look at the complete adsorption of the oil rather than focusing on certain components (as we did with GC), the results are shown in Figure 6.

Due to the differences in adsorption conditions in GC and FMC adsorption studies, it is not possible to make direct comparisons between the results. This is because the GC adsorption was under a closed system which would be able to reach equilibrium, where as the FMC 
work used a flow of EO probe allowing for constant replenishment of the concentration gradient. The FMC results suggest that Laponite ${ }^{\circledR}$ RD gave a greater level of adsorption than the other two substrates. The Laponites ${ }^{\circledR}$ appeared to be more receptive to OO and RO than MO possibly due to the higher number of large molecules found in MO. Another factor making the comparison between GC and FMC results difficult is that the FMC studies took into account the adsorption of all of the oil components, this is less likely to have an effect for RO as approximately $90 \%$ of the oil is linalool, but $\mathrm{MO}$ and $\mathrm{OO}$ are much more complex with a large amount of molecules with similar concentrations within the oil.

The levels of adsorption observed in the GC and FMC studies would suggest that adsorption was only taking place on the surface of the MMT materials, in order to achieve a reservoir of EO, the EO would need to be absorbed into the galleries between the MMT platelets. In addition to not achieving the desired levels of adsorption, it was also noted that $\mathrm{OO}$ and $\mathrm{RO}$ were adsorbed to considerably different levels. This would be a problem as the antimicrobial testing of the EO blend showed that the properties of an EO blend are affected by the ratio of the two oils. It is therefore important to use a substrate that adsorbs $\mathrm{RO}$ and $\mathrm{OO}$ to as even a level as possible, so as to not change the ratio of the EO in the blend during adsorption.

In an attempt to attain increased levels of adsorption, the three substrates were each organically modified. This was done to make the pores of the MMT more receptive to the high amounts of hydrophobic molecules contained within the oils. The Laponites ${ }^{\circledR}$ were treated with a dihydrogenated tallow dimethyl ammonium chloride (2HT2M) at 50, 75 and $100 \%$ cation exchange capacity (CEC) and Fulcat ${ }^{\circledR} 800$ was treated with a $2 \mathrm{HT} 2 \mathrm{M}$ and cetyltrimethylammonium bromide (CTAB) at 50, 75 and $100 \%$ CEC.

Each of these samples were analysed again using GC and FMC for adsorption of the three EO.

The GC analysis of the OM Fulcat ${ }^{\circledR} 800$ substrates showed that the level of adsorption was not improved compared to that achieved with the unmodified (UM) Fulcat ${ }^{\circledR} 800$. For all three types of modification a significant drop in the levels of adsorption of RO and MO was observed between the UM Fulcat ${ }^{\circledR} 800$ and the $50 \%$ CEC OM Fulcat ${ }^{\circledR} 800$. With increasing levels of modification a gradual increase in the amount of adsorption occurred for the two oils. The level of adsorption of MO appeared unaffected by the OM of the Fulcat ${ }^{\circledR} 800$ samples, staying around the $6 \%$ level achieved for the UM samples.

The OM Laponite ${ }^{\circledR}$ B samples followed a similar pattern to the Fulcat ${ }^{\circledR} 800$ substrates. The reduction in the level of adsorption caused initially by the OM is likely to be because 
the alkyl chains of the organic modifier have obscured the surfaces of the substrates restricting the amount of adsorption sites available for the EO molecules to attach to. The subsequent increase could then be explained by the increasing hydrophobic character of the galleries between the platelets resulting in a greater affinity for the EO molecules to enter the spaces of the galleries.

The OM Laponite ${ }^{\circledR}$ RD adsorption of MO (Figure 7) displayed a similar pattern to the other substrates tested with a decrease in the level of adsorption from UM to $50 \% \mathrm{OM}$ modification and then a slight increasing trend with increasing levels of OM. For the adsorption of $\mathrm{RO}$ and $\mathrm{OO}$ a different pattern was observed. Instead of the initial reduction with $50 \% \mathrm{OM}$ and then a general increase with increasing modification, RO displayed a general decreasing trend in the levels of adsorption with increasing levels of adsorption. In addition to this, the reduction in the level of adsorption from UM to 50\% OM was small. From UM Laponite ${ }^{\circledR} \mathrm{RD}$ to $50 \% \mathrm{OM}$ there was an approximate doubling of the amount of adsorption for $\mathrm{OO}$ followed by a downward trend in the level of adsorption with increasing modification. These results are significant for the EO used in the antimicrobial blend as for RO the levels of adsorption are maintained with OM while the OO showed an increase. Added to the $50 \%$ OM resulted in even levels of adsorption of the two blend oils, which is significant as it will result in the EO ratios in the blend being maintained during adsorption. There was a downward trend for Laponite ${ }^{\circledR} \mathrm{RD}$ with increasing levels of OM.



Figure 7: GC adsorption characteristics for unmodified (UM) and 50, 75 and 100\% CEC modified Laponite ${ }^{\mathbb{R}} \mathrm{RD}$ (mass of oil adsorbed/mass of substrate).

The FMC measurement of the OM substrates was only carried out on the $50 \%$ and $75 \% \mathrm{OM}$ samples, this was due to the $100 \%$ OM substrates forming a gel when the EO heptane solution was passed over them. This resulted in the FMC cell becoming blocked and prevented data being obtained. This gel formation is significant because it indicates 
interaction between the $\mathrm{EO}$ an $\mathrm{d}$ the $\mathrm{OM}$ samples As with the $\mathrm{GC}$ measurements, the general trend for the OM substrates was a reduction in the level of adsorption from $\mathrm{UM}$ to $50 \% \mathrm{OM}$ then a slight increase from $50 \%$ to $75 \%$. With the exception of Laponite ${ }^{\circledR}$ B which showed a second reduction from $50 \%$ to $75 \%$. The $50 \%$ OM Laponite ${ }^{\circledR}$ RD again gave even levels of adsorption of OO and RO (Figure 8). Had it been possible to examine the $100 \% \mathrm{OM}$ samples the levels of adsorption may have been even higher

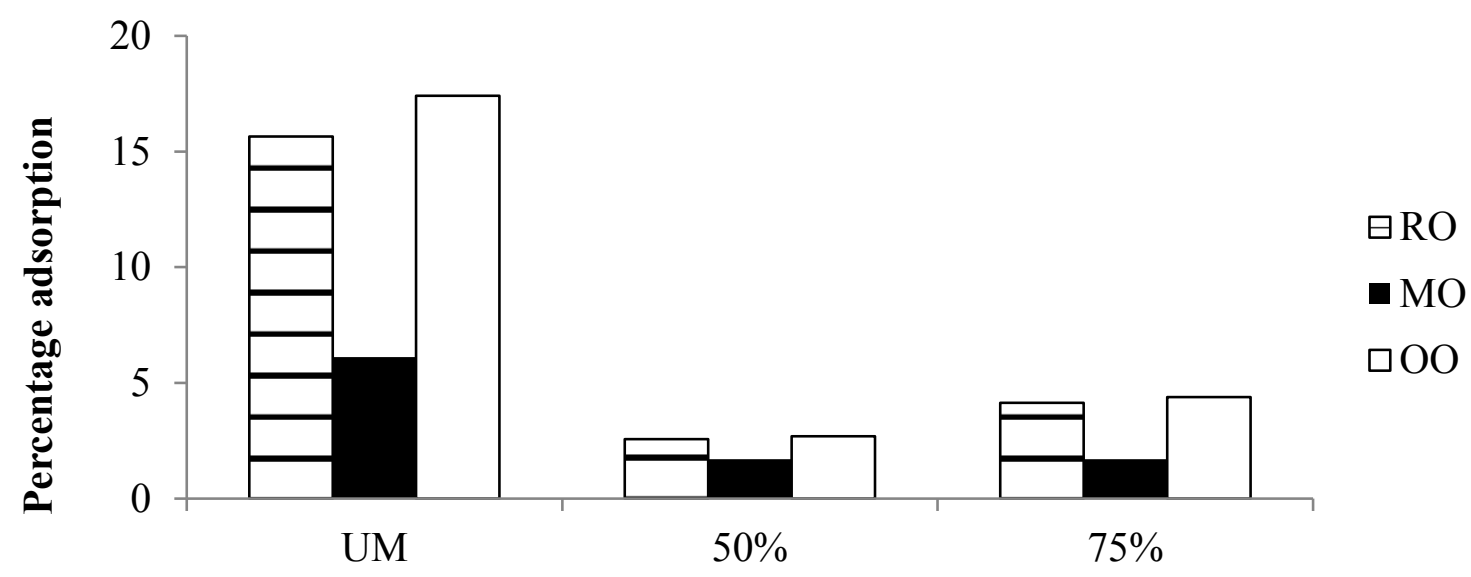

Figure 8: FMC adsorption characteristics for unmodified (UM) and 50 and 75\% CEC modified Laponite ${ }^{\circledR} \mathrm{RD}$ (mass of oil adsorbed/mass of substrate).

The adsorption results from the OM substrates, showed Laponite ${ }^{\circledR} \mathrm{RD} 50 \% \mathrm{OM}$ to be the most favorable. This is due to two factors: achieving similar or greater levels of adsorption of the EO compared to the UM substrate, and the increase in organic character of the substrate should result in a greater affinity for the EO molecules leading to slower release from the substrate. Therefore Laponite ${ }^{\circledR}$ RD OM with 50\% CEC 2HT2M was chosen to be used as the adsorption substrate for incorporating the EO into polymer materials.

The antibacterial testing of the EO polymers proved challenging. Normal disc diffusion methods were unsuitable due to the hydrophobic nature of the EO molecules preventing them from diffusing through aqueous media used. This led to the development of the method described at the end of the experimental section.

The results for the MRSA antimicrobial assays are shown in Figure 9. The pure silicone elastomer (SE) had no effect on the bacterial cells on the surface. With the number of viable (living) cells remaining around $10^{6}$ throughout the experiment (as was to be expected). The SE samples containing the EO all showed a large reduction in the number of viable bacterial cells immediately after the drying phase $($ time $=0)$ from $10^{6}$ to $10^{3}$ cells. $\mathrm{SE}+(\mathrm{LRD} 50+\mathrm{EO})$ 
showed the strongest effect producing almost a $4 \log$ reduction in the number of viable cells on the surface. Over the $24 \mathrm{~h}$ period analysed the number of viable bacterial cells on the surface showed a gradual increase after the initial large reduction. This is could be explained if the bacterial cells dried onto the SE surface in stacks. The cells towards the bottom of the stacks would be killed by the EO antimicrobial, but the cells higher up the stack would be far enough away to not be effected by the EO. Over the $24 \mathrm{~h}$ period these cells would be able to multiply slowly accounting for the increase in numbers observed. The $\mathrm{SE}+(\mathrm{LRD} 50+\mathrm{EO})$ resulted in the lowest number of viable cells on the surface after the 24 $\mathrm{h}$ observation period. This is to be expected as the SE samples with the EO adsorbed onto a substrate will have a more even distribution of the EO throughout the polymer matrix. Where as in the SE with the EO added directly there will be large areas of the EO surrounded by areas with no EO as the organic EO molecules will have limited miscibility with the SE. This will result in areas of the polymer having no antimicrobial activity allowing the bacteria in these areas to survive. The reason for the $\mathrm{SE}+(\mathrm{LRD} 50+\mathrm{EO})$ having slightly better activity that the $\mathrm{SE}+(\mathrm{LRD} 100+\mathrm{EO})$ is likely to be because the $\mathrm{SE}+(\mathrm{LRD} 50+\mathrm{EO})$ gives an overall higher level of adsorption resulting in more EO present in the material. The $\mathrm{SE}+(\mathrm{LRD} 100+\mathrm{EO})$ also has a greater organic character, this may lead to the EO components being too tightly bound within the substrate preventing them from leaching to the surface. These two factors will result in a slightly lower level of antimicrobial activity than $\mathrm{SE}+(\mathrm{LRD} 50+\mathrm{EO})$ which is seen with a greater number of viable cells left on the surface of the SE+(LRD100+EO) sample.

Figure 10 shows the results from the antimicrobial testing with Acinetobacter baumannii. As with the MRSA testing the SE samples containing EO showed a reduction in the number of viable cells immediately after the drying phase. The SE samples containing the EO adsorbed onto substrates performed better than the SE containing just the EO. Initially the $\mathrm{SE}+($ LRD100+EO) sample gave stronger antimicrobial activity than SE+(LRD50+EO), however over the 24 hour period the $\mathrm{SE}+(\mathrm{LRD} 100+\mathrm{EO})$ sample was better able to maintain a high level of antimicrobial activity. 


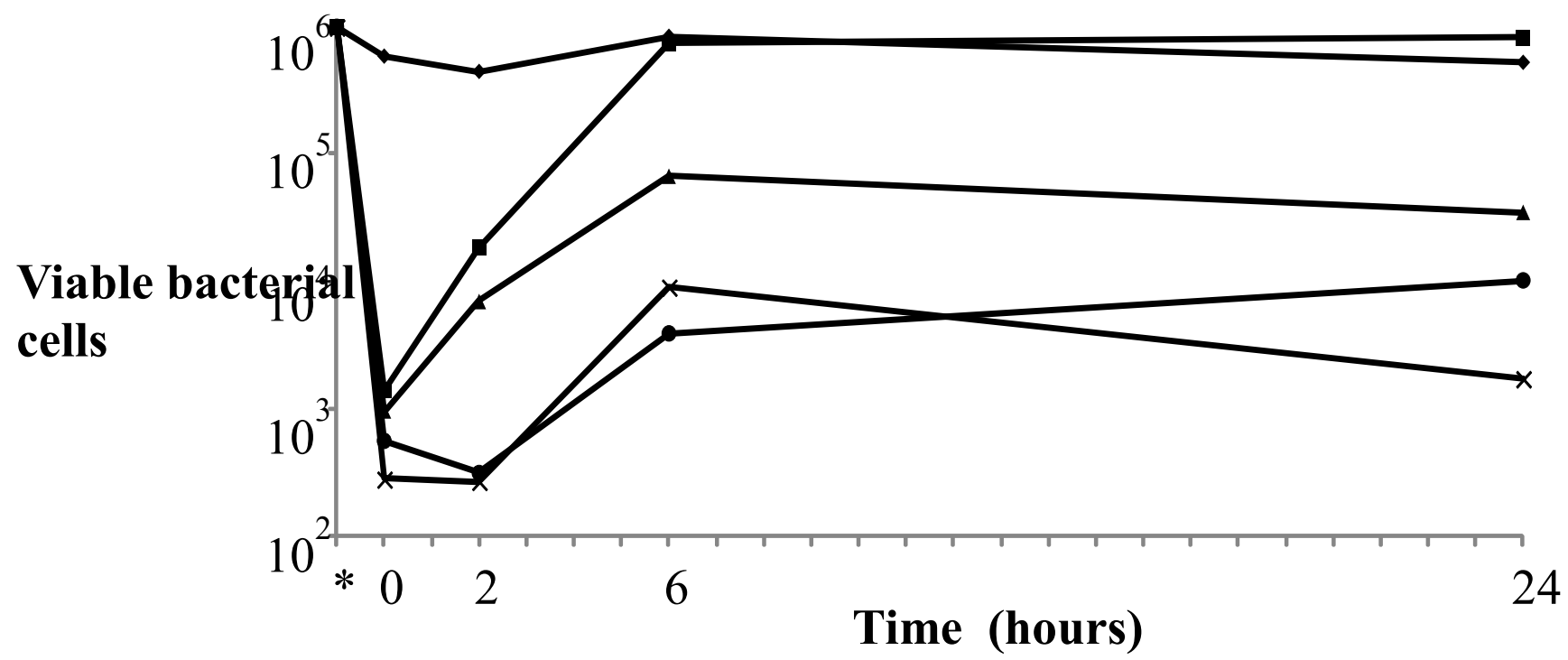

Figure 9. Antimicrobial testing data for MRSA on SE samples containing EO. Showing the reduction in live bacterial cells over time. - SE, $\boldsymbol{-}-\mathrm{SE}+\mathrm{LRD} 50, \boldsymbol{\Delta}-\mathrm{SE}+\mathrm{EO} . \mathbf{x}-\mathrm{SE}$ $+(\mathrm{LRD} 50+\mathrm{EO}), \bullet-\mathrm{SE}+(\mathrm{LRD} 100+\mathrm{EO}) .{ }^{*}$ indicates point of addition of bacterial cells before drying onto surface.

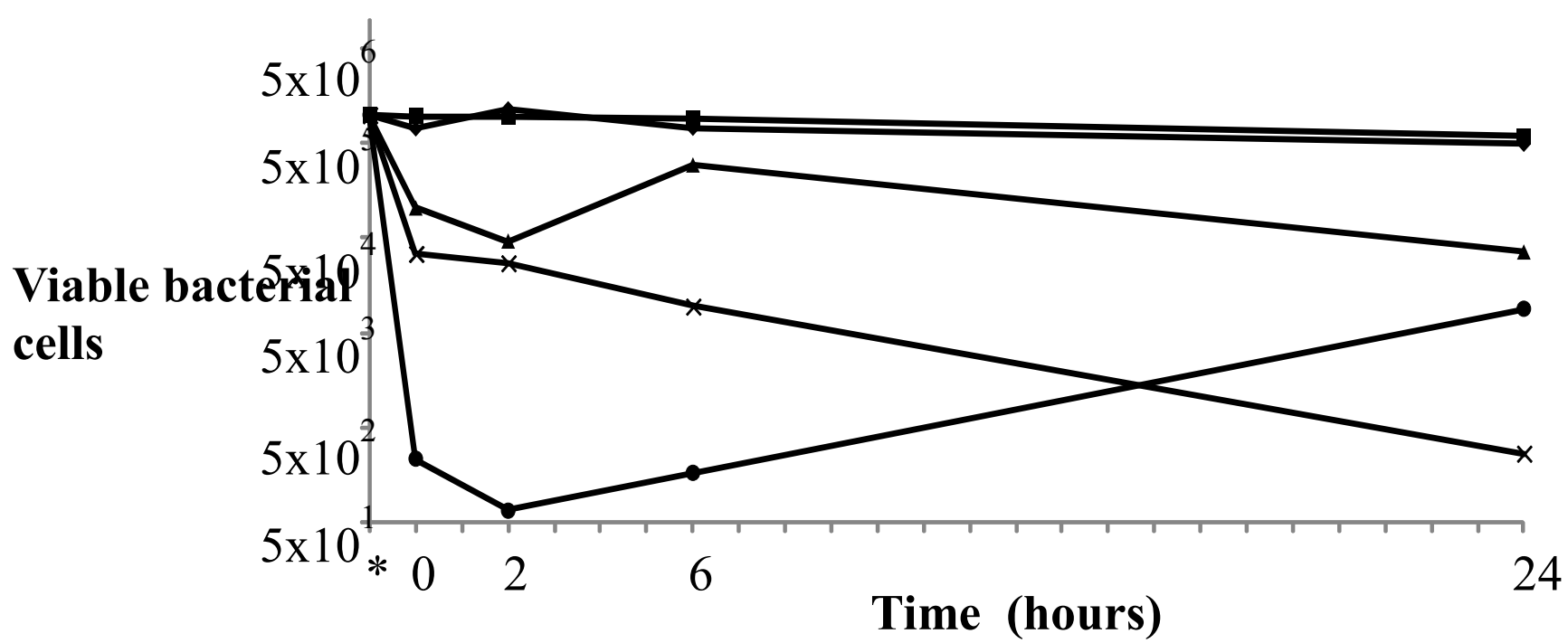

Figure 10: Antimicrobial testing data for Acinetobacter baumannii on SE samples containing EO. Showing the reduction in live bacterial cells over time. $-\mathrm{SE}, \mathbf{-}-\mathrm{SE}+$ LRD50, $\boldsymbol{\Delta}-\mathrm{SE}+\mathrm{EO} . \mathbf{x}-\mathrm{SE}+(\mathrm{LRD} 50+\mathrm{EO}), \bullet-\mathrm{SE}+(\mathrm{LRD} 100+\mathrm{EO}) . *$ indicates point of addition of bacterial cells before drying onto surface.

The results obtained from the antimicrobial testing show not only that the antimicrobial activity of the EO can be transferred to polymers, but also there is a strong benefit obtained from adsorbing the EO blend onto a substrate rather than adding the EO directly into the SE. 


\section{Conclusions}

This study has looked at EO antimicrobials and their suitability as additives to create polymers with inherent antimicrobial activity.

By blending together $\mathrm{OO}$ and $\mathrm{RO}$ we have obtained a natural antimicrobial that gives high levels of activity against a number of common HAI causing pathogens. After testing a number of porous silicate materials for adsorption of EO we have found that acid treated clays are not suitable as they cause damage to the EO molecules. Synthetic magnesium silicates $\left(\right.$ Laponites $\left.^{\circledR}\right)$ and a chemically modified alumino silicate $\left(\right.$ Fulcat $\left.^{\circledR}{ }^{\circledR} 800\right)$ have been shown to adsorb EO onto their surface; however absorption of the EO into the galleries of the silicates was not achieved.

In general OM of the silicate materials resulted in a reduction in the level of adsorption of the EO from heptane solution, due to adsorption sites on the surface of the silicates being occupied by the OM. However Laponite ${ }^{\circledR}$ RD with $50 \%$ CEC OM showed a number of promising benefits when compared to UM Laponite ${ }^{\circledR} \mathrm{RD}$. It is thought that by adjusting the OM further it may be possible to increase the level of adsorption further. adsorbing the $\mathrm{EO}$ on to $\mathrm{OM}$ Laponite ${ }^{\circledR} \mathrm{RD}$ it was possible to further enhance the antimicrobial properties afforded by the EO in the silicone elastomer. This is likely to be down to a more uniform distribution of the EO in the polymer and the added controlled release that is obtained by adsorbing the $\mathrm{EO}$ to a substrate.

[1] Healthcare-Associated Infections and Antimicrobial Resistance: 2009/2010. London, Health Protection Agency 2010.

[2] Hammer, K.A., et al., Journal of Applied Microbiology, 1999. 86(6): p. 985-990.

[3] Edwards-Jones, V., et al., Burns, 2004. 30(8): p. 772-777.

[4] Liauw, C.M., et al., Macromolecular Symposia Special Issue: Eurofillers, 2011. 301(1): p 96-103 